\title{
TOWARDS A CAPITATION FORMULA FOR COMPETING HEALTH INSURERS. AN EMPIRICAL ANALYSIS
}

\author{
René C. J. A. van Vliet and Wynand P. M. M. van de Ven \\ Department of Health Policy and Management, College of Medicine and Health Sciences, Erasmus \\ University, P.O. Box 1738, 3000 DR Rotterdam, The Netherlands
}

\begin{abstract}
In many countries the concept of capitating health care insurers is receiving increasing attention. The main reason is, that capitation may induce health care insurers in a competitive environment to concentrate more on cost containment. However, if the adjusters on which capitation payments are based, are too global, there may be ample room for risk selection by the insurers whilst also an unfair distribution of funds over the insurers may result, thereby undermining the objectives of capitation.

The prime motivation for the present study is, that the Dutch government, as part of proposals for a new, market oriented structure of health care system, is considering to capitate insurers on the basis of global parameters like age, gender and location. Our analysis based on panel data of some 35,000 individuals, shows that the proportion of variance in annual health care expenditures that can be predicted $\left(R^{2}\right)$ by such a global capitation formula, is only 0.024 . This is less than $1 / 5$ of our estimate of the theoretically maximum achievable $R^{2}$ which amounts to 0.138 , implying the existence of abundant selection opportunities, e.g. on the basis of past expenditures or other health indicators.

Alternative capitation formulae incorporating prior-year's costs and reaching about $3 / 5$ of the maximum obtainable $R^{2}$, effectively remove the profitableness of selection on the basis of past expenditures. The findings suggest, however, that selection via (chronic) health status may still be profitable to some extent. Therefore, we also analyzed data from the Dutch Health Interview Survey $(N \approx 20,000)$ which comprised better health indicators. It appeared that a capitation formula based on the global adjusters mentioned above as well as three health status indicators and several background characteristics, yields an $R^{2}$ of about 0.114 , which probably accounts for $3 / 4$ of our estimate of the maximum obtainable $R^{2}$.

The main conclusion is, that in the short term information on prior expenditures, which is available in the files of most insurers and thus may be used for risk selection, should be included in the capitation formula. For the more distant future, the formula should be expanded with indicators of chronic health status, possibly based on diagnostic information from previous, non-discretionary hospitalizations.
\end{abstract}

Key words -health insurance, capitation, risk selection

\section{INTRODUCTION}

In the United States of America (U.S.) it is well established among researchers, that the Adjusted Average Per Capita Cost (AAPCC) method used in the Medicare program for paying capitated delivery systems, is unfair and stimulates risk selection. Various studies have shown that major improvements can be achieved by extending the set of adjusters-which presently comprise age, gender, welfare status, institutional status and county-with measures of prior use or costs or, better still, measures fo chronic health status. In the Netherlands, however, we seem to be lagging behind some 10 years with respect to both the research in this area and the political discussion: while it seems generally acknowledged in the U.S. that the adjusters mentioned are insufficient, the Dutch government intends to use just these type of risk factors for capitating all health insurance organizations in a new, market oriented structure of the Dutch health care system [1].

\section{Policy proposals}

In the late 80's the Dutch government started the implementation of a national health insurance based on regulated competition in the private sector [1]. The benefits package will be broad, covering about $96 \%$ of all acute and long term care. Qualified insurers will receive for each of their insured a premium-replacing (capitation) payment from a Central Fund, which, in its turn, will be filled with mandatory income-dependent premiums, to be paid to the tax-collector. Qualified insurers are obliged to have an open enrolment period once every two years and to obey other procompetitive regulation. The capitation payment is independent of the chosen insurer and will be equal to the risk-adjusted per capita costs of the covered benefits for the risk group to which the insured belongs, minus a fixed amount. This fixed amount is equal for all individuals and will be about $11 \%$ of the average per capita costs of the covered benefits. The deficit created by this deducted fixed amount is met by a flat rate premium to be paid by the insureds directly to the insurer of their choice. The difference between the actual costs and the risk-adjusted capitation payment will not be the same for all insurers and will be reflected in the flat rate premium that the competing insurers will quote. This creates the incentive for insurers to be efficient. For sake of solidarity between healthy and unhealthy people an insurer is obliged to quote the same flat rate premium to all his insureds who choose the same insurance option. A 
voluntarily chosen deductible may reduce this premium. Insurers will be allowed to contract selectively with providers and to offer different insurance options as do, for instance, HMOs, preferred provider organisations or traditional health insurers, provided the insurance conditions conform to legally described insurance rights.

\section{Capitation payments}

The main objective of this article is to show that in the Dutch context global capitation formulae for acute care are inadequate because: (1) they are unfair, i.e. overpaying insurers with relatively healthy insureds and underpaying others; and (2) they encourage insurers to select against those whose health care costs are predictably above their capitation payment. A second objective is to investigate more comprehensive formulae that may reduce these problems. Procompetitive regulation as another strategy for reducing at least the consequences of the second problem, is not considered here [2].

To some extent this study, based on Dutch data, can be seen as a replication of similar U.S. studies. A major difference, however, is the combination of survey and claims data for a large group of people of all ages. The data sources provide the opportunity to study the predictive performance of capitation formulae based solely on claims data, for groups formed on survey information. This may indicate whether it is possible to construct a start-up capitation formula [3] based solely on (administrative) data that is already available, so that no additional data collection would be necessary.

The next section shows that global adjusters such as age, gender and region, leave substantial room for risk selection. The analysis uses a panel dataset comprising information over a period of 5 years on the annual health care expenditures of some 35,000 continuously enrolled privately insured individuals. For a subgroup $(N \approx 14,000)$ additional survey data is available on indicators of health status in the base year. The survey data is employed in the third section to assess the ability of capitation formulae based on claims data (namely prior costs), to predict [4] correctly the costs for groups formed on health status indicators. Subsequently, the addition of indicators of (chronic) health status to the set of global adjusters is investigated on the basis of cross-section data from the Dutch Health Interview Survey $(N \approx 20,000)$. In comparison to the panel dataset, more comprehensive health status indicators are available, thus providing the opportunity to explore the performance of capitation formulae based on, among other things, a crude variant of Diagnostic Cost Groups [4].

\section{GLOBAL CAPITATION}

\section{Panel data}

The panel data used in this section stem from "Zilveren Kruis", the largest private health insurance organization in the Netherlands. The data refer to some 50,000 insured individuals and comprise information on their annual health care expenditures and insurance coverage over a period of 5 consecutive years (1976-1980). To prevent interpretation problems, individuals who, for some reason or another, left the insurance organization during the 5-year period considered, are excluded from the analyses. This implies that approximately $30 \%$ of the observations are dropped [5] and therefore, the analyses are performed on data from about 35,000 individuals. The annual health care expenditures include the costs of inpatient room and board, and of both inpatient and outpatient specialist care and ancillaries. It does not comprise the cost of drugs prescribed by physicians and care provided by a family doctor because these are covered (and thus recorded by the insurance company) only for people with a supplementary G.P. insurance (about $40 \%$ of the insured). Also, those insured individuals with a supplementary luxury insurance, which covers the expenses of treatment in a (semi-) private room in the event of hospitalization, have higher total costs by definition because per-diem prices for this type of accommodation are higher.

In an explorative analysis, the 35,000 persons in the basic dataset have been classified into six groups according to their 1976 costs. Subsequently, their expenditures in following years have been computed. The so-called 'cost ratios' presented in Table 1 are defined as the average expenditures in the group

Table 1. Ratios of mean cost to overall mean cost for groups formed on 1976 cost

\begin{tabular}{|c|c|c|c|c|c|c|}
\hline \multicolumn{3}{|c|}{1976} & \multirow{2}{*}{\multicolumn{4}{|c|}{ Cost ratio $=$ group mean $/$ overall mean }} \\
\hline \multirow{2}{*}{$\begin{array}{l}\text { Cost interval } \\
\text { in Dff. }\end{array}$} & \multirow{2}{*}{$\begin{array}{c}N \\
(\%)\end{array}$} & \multirow{2}{*}{$\begin{array}{l}\text { Mean cost } \\
\text { in Df. }\end{array}$} & & & & \\
\hline & & & 1977 & 1978 & 1979 & 1980 \\
\hline 0 & $60.1 \%$ & 0 & 0.51 & 0.63 & 0.64 & 0.68 \\
\hline $1-250$ & 20.1 & 97 & $0.96^{n s}$ & $1.03^{\mathrm{ns}}$ & 1.12 & $1.02^{\mathrm{ns}}$ \\
\hline $251-500$ & 6.0 & 362 & 1.46 & 1.45 & 1.39 & 1.38 \\
\hline $501-1000$ & 5.1 & 698 & 1.95 & 2.07 & 1.85 & 1.85 \\
\hline $1001-2500$ & 3.8 & 1548 & 2.30 & 1.94 & 2.21 & 1.99 \\
\hline$>2500$ & 4.9 & 7417 & 4.61 & 3.03 & 2.64 & 2.71 \\
\hline Total & $(N=) 34,947$ & 497 & 1 & 1 & 1 & 1 \\
\hline Overall means ${ }^{b}$ & & & Df. .513 & Dfl.583 & Dfl.664 & Dft.779 \\
\hline
\end{tabular}

In Dutch florins; 1 U.S. dollar is worth about Dfl.1.90 (April 1991).

bThe last row gives overall mean costs for each of the 4 years.

${ }^{n}$ No statistically significant ( $t$-test, $P=0.05$ ) difference between group mean and overall mean. 
concerned divided by the average expenditures for all persons in that specific year. These ratios implicitly correct for inflation and for the effects of aging in the cohorts.

The cost ratios for the period 1977-1980 show a strong tendency to move towards the value of 1 . This is an illustration of the 'regression towards the mean' phenomenon: if people are grouped according to their health care expenditures in a certain year, the group means have a tendency to move towards the total mean over time [6]. However, the first row shows that individuals with zero expenditures in the base year are, on average, still $32 \%$ below the overall mean four years later. Those with expenditures above Dfl.2,500 in 1976 have $171 \%$ higher expenditure in 1980 than the average insured individual. Over the entire period of 4 years, the expenditures of the first group are $40 \%$ below, and those of the latter $200 \%$ above average.

These findings are comparable to those of Lubitz et al. [7] and Beebe [8]. Before drawing too strong a conclusion, one has to realize that older people are probably over-represented in the higher cost groups whilst the opposite holds for the lower cost groups. Below corrections for these and other differences in the composition of these groups will be studied.

\section{Theoretically maximum obtainable $R^{2}$}

It has been shown $[6,11]$ that there exists a theoretical upper bound on the percentage of variance in health care expenditures that one may ever hope to predict. Such a maximum can used as a yardstick for comparing $R^{2}$ s obtained in practice: the narrower the gap between this maximum and the $R^{2}$ for a certain capitation formula the smaller are the possibilities for risk selection. With panel data available, it is possible to estimate, on the basis of error components models, this theoretical maximum. We have tested three of the models that are suggested in the literature for this purpose on our panel dataset: a variance components model, an autoregressive model and a mixed autoregressive-variance components model. These models were, however, both theoretically and empirically outperformed by a combination of an autoregressive model with an (adjusted) first-order moving-average model. On the basis of that model the theoretical maximum $R^{2}$ was estimated bo be $13.8 \%$ [10]. This is comparable to other studies on this subject $[6,11]$.

\section{Global capitation formulae}

Table 2 gives the specifications of three global capitation formulae that were estimated on the panel dataset. The set of adjusters in these formulae is restricted to those risk factors that were initially considered by the Dutch government, i.e. age, sex, insurance coverage and region. The inclusion of insurance coverage and region in two of these models does not imply that insurers will be compensated completely for the extra costs associated with, for
Table 2. Three alternative models for capitation formulae

\begin{tabular}{lccc}
\hline Adjusters & I & II & III \\
\hline Age/sex (31 dummies) & $\mathrm{X}$ & $\mathrm{X}$ & $\mathrm{X}$ \\
Supplementary insurance & & $\mathrm{X}$ & $\mathrm{X}$ \\
Province (11 dummies) & & & $\mathrm{X}$ \\
Explained variance $\left(R^{2} \times 100\right)$ & $2.0 \%$ & $2.3 \%$ & $2.4 \%$ \\
\hline
\end{tabular}

'Results are from linear regressions of expenditures on the respective sets of risk factors, estimated by OLS on all available personyears of data $(N \approx 200,000)$.

This concerned two dummy variables that indicate whether one has a supplementary insurance for GP care and prescription drugs, and whether one is covered for the extra costs of treatment in a (semi-) private room in the event of hospitalization.

instance, the possibility of a higher propensity to consume medical care by people with GP insurance or living in certain areas. In general, as far as these and other effects do not reflect differences in health status they should not be accounted for at all [9]. However, in view of the degree of acceptance of a capitation formula when introduced, it seems imperative to allow for these effects completely, at least in the short term.

The bottom line of Table 2 shows that age and sex explain $2.0 \%$ of the expenditure variance, or about $1 / 7$ of our estimate of the maximum explainable variance $(=13.8 \%)$. This is somewhat better than the findings with respect to the AAPCC variables presented by Lubitz et al. [7] and Newhouse et al. [11], who reported $R^{2}$ values of around $1 \%$. The higher $R^{2}$ value can be traced to: (1) the more elaborate specification of age and sex in our study (with 31 dummies); and (2) the fact that we analyze all age-groups, whereas Lubitz et al. study people of 65 years and over, and Newhouse $e t$ al. analyze people between 14 and 65 years old. The variance explained by the least global of the three models in Table 2 amounts to only about $1 / 6$ of the maximum, thus probably leaving substantial room for risk selection. In the next subsection we shall investigate the opportunities for risk selection using prior costs and health indicators, given a global model.

\section{Predictive performance}

Employing the global capitation formula given by model III, the cost ratios of Table 1 have been recalculated. The cost ratio for a particular group is now defined as the quotient of the mean costs actually incurred by that group and the mean costs predicted by model III (Table 3). In this way, differences in composition among the groups with respect to age, sex, insurance coverage and region are accounted for. The results suggest that the highest cost group probably comprises a large proportion of older people since in comparison to Table 1 the cost ratios for this group have dropped markedly. As expected, the cost ratios of most groups in most years have moved closer to one. Also, the number of cost ratios that do not differ significantly from one, has increased. However, the results are of the same tenor: the sharpest movement towards the mean occurs in the first year 
Table 3. Ratios of actual to predicted mean costs (model III) for groups formed on 1976 cost $^{2}$

\begin{tabular}{|c|c|c|c|c|c|c|}
\hline \multicolumn{3}{|c|}{1976} & \multirow{2}{*}{\multicolumn{4}{|c|}{ Cost ratio $=$ actual $/$ predicted group mean }} \\
\hline \multirow{2}{*}{$\begin{array}{l}\text { Cost interval } \\
\text { in Df. }\end{array}$} & \multirow{2}{*}{$\begin{array}{c}N \\
(\%)\end{array}$} & \multirow{2}{*}{$\begin{array}{c}\text { Mcan cost } \\
\text { in Df. }\end{array}$} & & & & \\
\hline & & & 1977 & 1978 & 1979 & 1980 \\
\hline \multicolumn{7}{|l|}{ Total cosis } \\
\hline 0 & $60.1 \%$ & 0 & 0.57 & 0.70 & 0.71 & 0.76 \\
\hline $1-250$ & 20.1 & 97 & $0.92^{\mathrm{ns}}$ & $0.99^{\text {ns }}$ & $1.08^{\text {ns }}$ & $0.98^{\mathrm{ns}}$ \\
\hline $251-500$ & 6.0 & 362 & 1.22 & 1.21 & $1.15^{\mathrm{ns}}$ & $1.15^{\mathrm{ns}}$ \\
\hline $501-1000$ & -5.1 & 698 & 1.58 & 1.67 & 1.50 & 1.49 \\
\hline $100 t-2500$ & 3.8 & 1584 & 1.93 & 1.64 & 1.87 & 1.70 \\
\hline$>2500$ & 4.9 & 7417 & 3.30 & 2.16 & 1.88 & 1.93 \\
\hline \multicolumn{7}{|l|}{ Inparient costs } \\
\hline 0 & $91.1 \%$ & 101 & 0.79 & 0.90 & 0.92 & 0.92 \\
\hline $1-2500$ & 4.7 & 1452 & 1.93 & 1.39 & 1.35 & 1.43 \\
\hline$>2500$ & 4.2 & 8021 & 3.41 & 2.10 & 1.84 & 1.82 \\
\hline \multicolumn{7}{|c|}{ Outpatient costs } \\
\hline 0 & $61.3 \%$ & 48 & 0.61 & 0.71 & 0.72 & 0.77 \\
\hline $1-500$ & 30.2 & 653 & 1.47 & 1.10 & 1.14 & $1.07^{\mathrm{ns}}$ \\
\hline$>500$ & 8.4 & 3221 & 2.37 & 2.09 & 1.96 & 1.92 \\
\hline
\end{tabular}

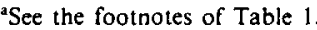

${ }^{n s}$ No statistically significant $(t$-test, $P=0.05)$ difference between actual and predicted mean cost

after the base year, after that the lowest and highest cost groups continue to move towards the mean but at a much slower pace. From the perspective of an insurance company, individuals in the group with zero costs in 1976 represent good risks, those with costs above the 1976 average Dfl.500 are bad risks. In the four year period after 1976, selection in favour of people from the zero-cost group would yield an insurance company an average profit of about $30 \%$ on the (global) capitation payment. Selection against people from the groups above Dfl. 500 would result in avoiding a loss of over $50 \%$ per person per year for the period after 1976. Even if there occurs further regression towards the mean after 1980, the gains in this four year period seem lucrative enough for insurers to consider selection strategies.

Table 3 also shows cost ratios for groups that are formed on inpatient and outpatient costs in 1976. In the long term the predictive value of outpatient costs in the base year appears to be larger than that of inpatient cost. For example, the cost ratio in 1980 for individuals with 1976 inpatient costs above Dfl.2,500 is 1.82 , whereas the (larger) group with 1976 outpatient costs above Dfl.500 has a cost ratio of 1.92 in 1980. Similarly, the fact that certain people have zero inpatient costs in 1976 is less informative for predicting future health expenditures (the ratio in 1980 is 0.92 ) than are zero outpatient costs (the ratio in 1980 is 0.77 ).

Previous studies have suggested that various aspects of outpatient care, such as psychiatric care and physiotherapy, may he highly correlated with permanent health status (e.g. Ref. [12]). Separate analyses for both cost components, showed that indeed anyone who incurred expenditure in 1976 for these types of care, had higher than expected total costs in each of the four subsequent years. In the last year (1980) the differences were still $50 \%$ for psychiatry and $100 \%$ for physiotherapy.

The conclusion is that, given global capitation payments, health care expenditures in a certain base year have predictive value over a period of four years. Since the trends in cost ratios are rather stable, the same conclusion may hold for even longer periods. This clearly shows that in this situation insurers are able to identify from among their insured population those individuals who can be expected to have future costs that are consistently above or below their capitation payment. Since this type of data is readily available to insurance companies, it is not too far fetched to imagine that they will implement selection strategies based on this information. Thus, a global model is inadequate with respect to the prevention of selection opportunities. It is important to ask what insurers may gain by risk selection, when the capitation formula also takes total prior costs and health status into account. In the next sections this issue will be addressed.

\section{CAPITATION FORMULAE INCORPORATING PRIOR COSTS}

\section{Longitudinal and survey data}

In this section we address two questions: (1) how close can a formula comprising prior costs and some global adjusters achieve the theoretical maximum $R^{2}$ of 0.138 ?; and (2) if there remains a gap between explained variance and its theoretical maximum, how can insurers take advantage of it? Presumably, the best opportunities for risk selection, when this more refined capitation formula is implemented, lie in using better indicators of permanent health status. This section addresses these questions using that part of the database for which we have additional data from a postal enquiry held in the base year, 1976 $(N \approx 14,000)$. The extra information refers to health status (number of days of illness in 6 months and perceived health status relative to the previous 2 years), medical consumption (number of consultations with the family doctor and medical specialists in 6 months, and costs of drugs prescribed by 
Table 4. Ratios of actual to predicted mean costs (model III-2) for groups formed on various indicators of health status in $1976^{\circ}$

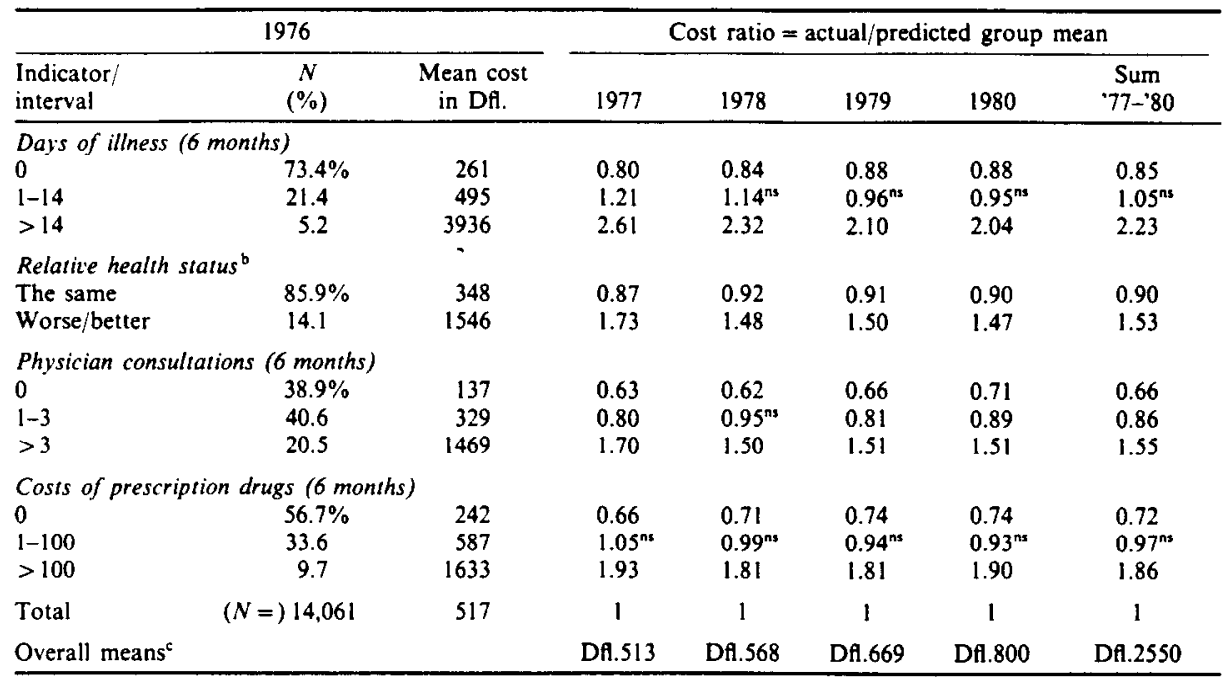

${ }^{2}$ Predicted costs are calculated on the basis of age, gender, insurance coverage and region (model III-2 of Table 5).

bealth status in the last six months relative to that in the preceding 2 years (self-rated).

'The last row gives overall mean costs for each of the 4 years.

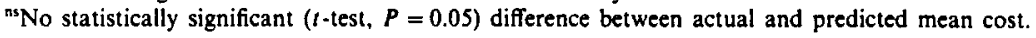

physicians in 6 months), and socio-economic status (income, education and employment status).

First we look at the ratio of actual to predicted costs for groups formed on the four health indicators and consumption variables mentioned above, where prediction is based on age, gender, insurance coverage and region (Table 4). This provides a base for studying similar ratios with more precise predictions. We shall interpret the two consumption variables as health indicators as well, because many studies have found strong correlations between health status and outpatient care, especially prescription drugs (e.g. Refs $[12,13])$.

Table 4 indicates that the number of days of illness in the first half of 1976, is still informative with regard to health care expenditures after a period of 4 years: individuals without illness and those with more than 2 weeks of illness have expenditures in 1980 that are respectively $12 \%$ lower and $104 \%$ higher than expected in view of their age, gender, insurance coverage and region. Also, there is little movement of the cost ratios towards the overall value of 1 after 1978.

The interpretation of the variable "health status in the last 6 months relative to that of the preceding 2 years" is not straightforward because no information is available on health status before 1976. However, it seems reasonable to assume that those individuals who indicate that their health has changed (either deteriorated or improved) have a general health status that is below average. This assumption is supported by the finding that the mean health care expenditures in 1976 for this group are well above average (column 3 of Table 4). Besides, this variable proves to be a predictor of future costs as cost ratios are consistently above 1 for the rest of the study period.
Table 4 also shows the predictive value of outpatient care; individuals with an above average number of physician consultations in the first half of 1976 , have $51 \%$ higher health care expenditure in 1980 than predicted. Hardly any regression of the ratios towards the value of 1 occurs after 1978. A similar pattern can be observed for prescription drugs, where it is remarkable that individuals with more than Dfl. 100 expenses on this type of care in the base year have between $81 \%$ and $93 \%$ higher costs in the following four years, without there being a noticeable declining trend. Similarly, the ratios for the group without prescription drugs vary between 0.66 and 0.74 , also without a discernible trend. This supports the hypothesis that prescription drugs are a fairly good indicator of chronic health.

Summarizing, the results show that each of the four health indicators has substantial predictive value in addition to the four global adjusters. The cost ratios for groups formed on the health indicators appear to level out after 1978, which is sooner than for the components of 1976 costs studied in Table 3. This suggests that the former are better predictors, with effects that may remain long after the study period. However, in view of the opportunities for manipulation of this type of information by insurers combined with problems of data-collection for the two direct health indicators, such information does not seem to qualify as adjuster in the capitation formula, at least not in the short term and in the present form.

\section{Capitation formulae extended with prior costs}

We shall now investigate more elaborate capitation. formulae using the reduced dataset for which survey data is available. For reasons of comparison we start again with the least global of the three models of 
Table 2, which were estimated on the complete database, i.e. model III. This model is denoted here by III-2. Apart from the fact that we now use a subgroup of the original database, there is also a difference in the statistical model: the formulae of Table 2 were obtained from linear regressions whereas all formulae in the present section are estimated by means of a so-called two-part model. In an explorative, split-sample analysis using this dataset we studied the performance of several commonly used statistical models by which individual annual health care expenditures can be related to explanatory variables [14]. The two-part model (with smearing estimator) was selected on the basis of the mean forecast error and the percentage of variance predicted. This model involves the cstimation of separate equations for the probability of having non-zero annual expenditures and, given positive expenditures, for the logarithm of expenditures.

The $R^{2}$ value for model 11 I-2 is, as it should be, almost equal to that of the corresponding model III of the previous section. Models IV and $\mathrm{V}$ are minor extensions of III-2. The first also includes employment status and family size, two of the adjusters suggested by a Dutch research institute that might remedy selection opportunities inherent to model III-2 [15]. Model $\mathrm{V}$ is additionally based on socioeconomic status (indicated by income and education), and degree of urbanization. Each of these adjusters may be seen as an indirect indicator of health status, which may perhaps be measured more reliably than direct indicators of health status such as the presence/absence of certain chronic conditions. The additional adjusters in the two models appear to give marginal improvements in $R^{2}$. Since the insured individuals in this particular database are mainly from the higher socio-economic classes, and whilst, moreover, they live primarily in the western part of the country, it is not justifiable to conclude from these results that such information is irrelevant with respect to capitation.

As well as age, gender, insurance coverage, and region, model VI contains information on total prior costs. In view of the data that is presently recorded by Dutch (private) insurance companies, this model seems feasible as a capitation formula. The $R^{2}$ value amounts to about $55 \%$ of the maximum achievable $R^{2}$. This is compariable to the results reported by Newhouse et al. [11] for a similar model. In this model the elasticity of capitation payment with respect to prior costs equals about 0.25 . Thus, the cost-containment incentive for insurers would be only marginally affected when capitation were based on this model.

Model VII differs from VI in that outpatient and inpatient care are distinguished and where, moreover, the former adjuster is broken down into five components. This model may not qualify as a capitation formula when these components have different effects on capitation payments, because that would create possibilities for manipulation. However, this type of data may be used by insurers to outperform the actual capitation formula, i.e. to distinguish good and bad risks among their insured populations. The same arguments hold for model VIII, which includes the four indicators of health status in 1976, as well as the information contained in models $\mathrm{V}$ and VII. The refinements of models VII and VIII yield only small increases in the percentage of explained variance as compared to model VI. Despite these small

Table 5. Six alternative models for capitation formulae

\begin{tabular}{|c|c|c|c|c|c|c|}
\hline Adjusters & III-2 & IV & V & VI & VII & VIII \\
\hline $\begin{array}{l}\text { Age/sex } \\
\text { supplementary insurance } \\
\text { province } \\
\text { Employment status } \\
\text { family size } \\
\text { Income } \\
\text { education level } \\
\text { degree of urbanization ( } 3 \text { dummies) } \\
\text { Prior-ycar's total costs (yes } / \text { no and } \log 1>0)^{\mathrm{b}} \\
\text { Prior-year's outpatient costs: } \\
\text {-physiotherapy (yes/no) } \\
\text {-psychiatry (yes/no) } \\
\text {--medical devices }(\text { yes } / \text { no) } \\
\text {-rest of outpatient costs }(\text { yes/no and } \log \mid>0)^{\mathrm{b}} \\
\text { Prior-year's inpatient costs }(\text { yes/no and } \log \mid>0)^{\mathrm{b}} \\
\text { - Days of illness (log }+1)^{\mathrm{c}} \\
\text { Relative health (dummy) } \\
\text { Physician consultations }(\log +1)^{\mathrm{c}} \\
\text { Prescription drugs (log }+1)^{\mathrm{c}}\end{array}$ & $\begin{array}{l}X \\
X \\
X\end{array}$ & $\begin{array}{l}\mathrm{X} \\
\mathrm{X} \\
\mathrm{X} \\
\mathrm{X} \\
\mathrm{X}\end{array}$ & $\begin{array}{l}X \\
X \\
X \\
X \\
X \\
X \\
X \\
X\end{array}$ & $\begin{array}{l}X \\
X \\
X\end{array}$ & $\begin{array}{l}X \\
X \\
X \\
X \\
X\end{array}$ & $\begin{array}{l}X \\
X \\
X \\
X \\
X \\
X \\
X \\
X \\
X\end{array}$ \\
\hline Explained variance $\left(R^{2} \times 100\right)$ & $2.4 \%$ & $2.7 \%$ & $2.7 \%$ & $7.2 \%$ & $7.3 \%$ & $7.4 \%$ \\
\hline
\end{tabular}

Every model is estimated for each of the four years $(1977-1980)$ by means of the two-part method described in the text $(N \approx 14,000)$. The $R^{2}$ values reported are averages for the 4 years, where the $R^{2}$ for a single year is defined as 1 minus the ratio of residual variance to total variance.

'These prior cost variables are entered in both parts of the models concerned in the form of a dummy variable, indicating whether prior costs were zero, plus a variable that equals the logarithmic of these costs in case of non-zero costs.

'These adjusters refer to 1976 . 
improvements it may well be that these later models provide better cost estimates for groups that are most vulnerable to selection, i.e. people with chronic conditions. In this type of analysis, the explained variance-which is a quadratic measure of deviations-does not seem to be best criterion for judging the performance of rival models. Rather, the ability to predict correctly the costs for people with chronic conditions is of prime importance, i.e. a linear measure of deviations. The next subsection explores this subject.

The proportion of variance explained by models VI and VII seems to indicate that even formulae based on prior expenditure leave ample room for risk selection. This may be caused by the large random variation in this adjuster: some people have high previous costs because of chronic conditions; for most others this is purely by chance. Consequently, a capitation formula including prior-year's costs will systematically underpay the insurer for the former group, and overpay for the latter, this latter group having a different composition each year [16]. Thus, selection against people with chronic conditions will remain profitable. A possible solution to this problem is to adjust the capitation payment for (indicators of) chronic health. This option will be explored in the next section.

\section{Predictive performance}

The important difference between claims data and survey data, such as days of illness or self-perceived health status, is that it will be harder to incorporate the latter type of information into a capitation formula whilst it is conceivable that insurers can obtain similar information-for instance in an HMO-setting - and use it to select risks. Therefore, it is important to investigate to what extent capitation formulae based on claims data can correctly predict expenditures for groups formed on health status, for example indicated by the variables analyzed in Table 4 . The cost ratios presented in that table have been recalculated, where predicted costs are now also based on prior total costs (Table 6).

Comparing the cost ratios of Table 6 with those of Table 4 , reveals that model VI provides better predictions for the groups concerned than the global model III-2. For example, only 4, instead of 9 , our of the 12 cost ratios for the groups formed on days of illness are now statistically significant, and nearly all cost ratios have moved closer to 1 . The group with more than two weeks of illness in 1976 is the only one for which there remain significant differences in each of the years after 1977. In 1980 this (small) group still has $54 \%$ higher costs than predicted, although this is substantially better than the $104 \%$ found in case of prediction via model III-2. Over the whole four year period actual costs for this group are $44 \%$ above predicted costs.

The cost ratios for 1980 for groups formed on relative health status have moved from 0.90 and 1.47 for the global model III-2, to 0.94 and 1.22 for model VI comprising prior costs as well as the four global adjusters. Besides, only one of the ratios remains significant.

The cost ratios for groups formed on physician consultations in 1976 also show major improvements: the number of significant ratios is reduced from 11 to 6 while all the ratios have moved towards 1 . The group without consultations has a (significant) cost ratio in the last year of the study period of 0.86 as compared to 0.71 in Table 4 . In that year the group with the most consultations has $21 \%$ more costs than expected as compared to $51 \%$ in Table 4 .

Table 6. Ratios of actual to predicted mean costs (model VI) for groups formed on various indicators of health status in $1976^{\mathrm{a}}$

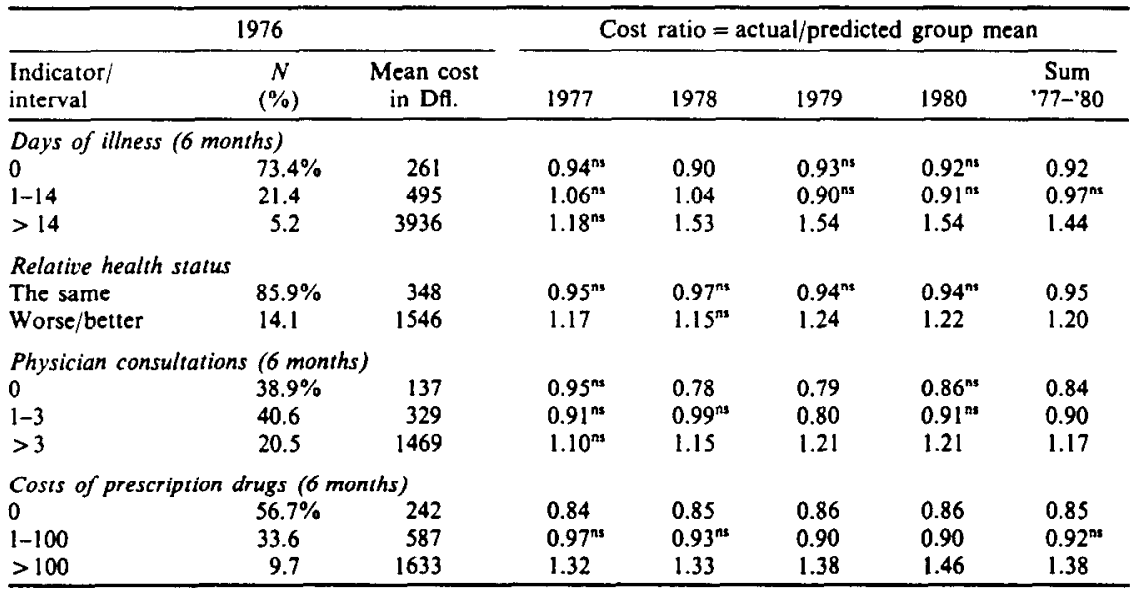

'Predicted costs are calculated on the basis of age, gender, insurance coverage, region and prior total costs (model VI of Table 5). Predictions for 1976 could not be calculated because no information was available on (prior) costs in 1975. The ratios in the last column are defined as the quotient of actual costs in the period 1977-1980 and predicted costs in that period.

${ }^{n}$ No statistically significant $(t$-test, $P=0.05)$ difference between actual and predicted mean cost. 
The least improvement has occurred for groups formed on prescription drugs: the number of significant ratios has dropped with only 2 in comparison to Table 4. Moreover, the group with zero expenditures on prescription drugs in 1976 has about $15 \%$ lower total costs than predicted in each of the four subsequent years (this percentage is statistically significant); this was about $25 \%$ when prediction was not based on prior costs. For the group with the most prescribed drugs these figures are $35 \%$ and $85 \%$ respectively.

Finally, Table 7 summarizes for nine groups the cost ratios for the last year of the study period, resulting from three models: a rudimentary model that does not contain any adjusters at all, the global model III-2 and model VI, comprising prior costs. The table shows that the profits (for insurers) on the zero cost groups reduce with about a factor $1 / 3$ when going from the simple model to the global model and fall further with about $1 / 2$ when prior costs are also taken into account. Similarly, the losses on the groups with the highest costs reduce with factors $1 / 2$ and $1 / 2$. Note that of the three grouping variables prescription drugs has the strongest predictive value: the ratio in model VI for the group without drugs is lower than those for the zero cost groups while the opposite holds for the group with the most drugs.

Summarizing, the findings of this section indicate that the addition of prior costs to the global capitation formula yields a major improvement in predictive ability. The potential profits and losses that insurers could incur for the groups that we have distinguished here, are about half of those in case of the global model III-2. However, there are still groups, identifiable via health status indicators, for which insurers are systematically overpaid or underpaid. The cost ratios for the four-rather crudeindicators of health status analyzed in this section, suggest that, in those groups that are underpaid by an extended capitation formula, individuals with chronic conditions are over-represented. The relevance of this finding is that presently many Dutch insurers have similar or even better indicators of chronic health status at their disposal, for example past expenses on prescription drugs and the diagnostic information of previous hospitalizations. It would be interesting to investigate the predictive ability of the latter type of data, for example by using the method of Diagnostic Cost Groups [4]. Unfortunately, the datasets analyzed in this article do not contain such information.

\section{CAPITATION PAYMENTS INCORPORATING HEALTH INDICATORS}

\section{Survey data}

This section, based on van Vliet [13], examines the performance of capitation formulae incorporating measures of chronic health status as well as the potential benefits insurers could pocket if they were able to select on the basis of health indicators, given a global capitation payment. The analysis uses data from the Health Interview Survey (HIS), which is held annually by the Central Burcau of Statistics among representative samples of the non-institutionalized Dutch population. This article employs information from the about 20,000 respondents from 1981 and 1982. The inquiry contains questions about health status, several background characteristics, and about the use of various medical care facilities, i.e. physiotherapy, GP care, prescription drugs, outpatient care by medical specialists and inpatient care. For the present study this information is comprised in an index of health care expenditures by combining utilization data with average prices.

The HIS dataset has several advantages in comparison with the dataset analyzed in the previous sections: (1) it comprises information on a representative sample of the entire Dutch population and not just the insured individuals of one particular private health insurance organization; (2) it contains various indicators of (chronic) health conditions; and (3) more data on background characteristics is available. A major disadvantages of the HIS dataset is, that it does not contain longitudinal data on health care expenditures [18].

Table 7. Ratios of actual to predicted mean costs in 1980 for 3 models

\begin{tabular}{|c|c|c|c|c|c|}
\hline \multicolumn{3}{|c|}{1976} & \multirow{2}{*}{\multicolumn{3}{|c|}{ Cost ratio $=$ actual $/$ predicted group mean }} \\
\hline \multirow{2}{*}{$\begin{array}{l}\text { Indicator } \\
\text { interval }\end{array}$} & \multirow{2}{*}{$\begin{array}{c}N \\
(\%)\end{array}$} & \multirow{2}{*}{$\begin{array}{l}\text { Mean cost } \\
\text { in Df. }\end{array}$} & & & \\
\hline & & & No adjusters & Model III-2 & Model VI \\
\hline \multicolumn{6}{|l|}{$\overline{\text { Total costs }}$} \\
\hline 0 & $56.3 \%$ & 0 & 0.69 & 0.77 & $0.93^{\text {ns }}$ \\
\hline $1-1000$ & 34.5 & 241 & 1.16 & $1.06^{n s}$ & $0.95^{n s}$ \\
\hline$>1000$ & 9.2 & 4716 & 2.33 & 1.79 & 1.31 \\
\hline \multicolumn{6}{|c|}{ Outpatient costs } \\
\hline 0 & $57.2 \%$ & 31 & 0.69 & 0.77 & $0.93^{n s}$ \\
\hline $1-500$ & 33.5 & 605 & 1.06 & $0.98^{\mathrm{ns}}$ & $0.91^{\mathrm{ns}}$ \\
\hline$>500$ & 9.4 & 3162 & 2.69 & 1.94 & 1.35 \\
\hline \multicolumn{6}{|c|}{ Costs of prescription drugs } \\
\hline 0 & $56.7 \%$ & 242 & 0.63 & 0.74 & 0.86 \\
\hline $1-100$ & 33.6 & 587 & 0.96 & $0.93^{\mathrm{ns}}$ & 0.90 \\
\hline$>100$ & 9.7 & 1633 & 3.01 & 1.90 & 1.46 \\
\hline
\end{tabular}


It should be stressed here that the analyses in this section serve as an illustration of the predictive value of various proxies of chronic health status, i.e.: proxies for the actual information either insurers or the Central Fund that is responsible for the capitation system, could have excess to (e.g. prior cost or diagnostic information). We are not suggesting that either parties could or should obtain the type of survey data used here.

\section{Capitation formulae based on health indicators}

Below we discuss seven capitation formulae containing various combinations of the risk factors available in the HIS dataset. The underlying models are not estimated, as in the previous section, by means of a two-part model, but via a four-part model, i.e. a two-part model for outpatient care and a separate two-part model for inpatient care. The main reason for this is a difference in time periods: outpatient care refers to the 3 months before the survey, whereas inpatient care refers to a 12 month period. The denotation in Table 8 of the seven alternative formulae corresponds with that of the previous sections, with models III-3, IV-2 and V-2 being versions of III, IV and V respectively, estimated on this dataset.

Model III-3 is included in the analysis for reasons of comparison with models III and III-2 of the previous sections. The explained variance of model III-3 is almost equal to that of the two latter models, despite the above mentioned differences between the datasets on which the respective models are estimated. This suggests, that the strength of the relationship of the independent variables to both expenditure and utilization, is about the same. The results for models IV-2 and V-2, which are similar to models IV and $\mathrm{V}$ of Table 5 and give comparable $R^{2}$ values, supports this hypothesis. Our opinion is, therefore, that conclusions obtained from the two datasets are to a large extent comparable.

The difference in fit between models V-2 and III-3 illustrates that background characteristics may indeed play a role in a global capitation formula. This difference is considerably greater than that between similar models in the previous section, which is caused by the non-representative nature of the panel dataset analyzed there.

Model V-2 is an extension of model IV-2 with a broad spectrum of background characteristics instead of health indicators. This model is motivated by the idea that it might be possible to capture the effect of health status on health care expenditures by means of-measurable-variables that underlie health status itself, i.e. indirect health indicators [15]. The model, which also includes additional insurance variables as well as supply factors, yiclds an $R^{2}$ value that is about half that for model IX, incorporating indicators of chronic conditions. This indicates that it is impossible to construct an adequate capitation formula that prevents risk selection without good indicators of health status.

Models IX and $\mathrm{X}$ are other extensions of the basic model IV-2 in that they also contain indicators of chronic health status, i.e. chronic conditions weighted with expected costs, and physical impairments. The explained variance of these models shows the relevance of health with respect to costs: the $R^{2}$ values are $2-3$ times as high as those for the models without health status indicators. Moreover, the $R^{2}$ for model

Table 8. Seven alternative models for capitation formulae

\begin{tabular}{|c|c|c|c|c|c|c|c|}
\hline Adjusters & III-3 & IV - 2 & $V-2$ & IX & $x$ & $\mathrm{XI}$ & XII \\
\hline $\begin{array}{l}\text { Age/sex } \\
\text { Insurance coverage } \\
\text { Region } \\
\text { Employment status } \\
\text { Family size } \\
\text { Socio-economic status } \\
\text { Body weight } \\
\text { Degree of urbanization } \\
\text { Supply of care facilities } \\
\text { Additional insurance coverage } \\
\text { Chronic conditions (weighted) } \\
\text { Physical impairments } \\
\text { Self-rated general health status }\end{array}$ & $\begin{array}{l}\mathrm{X} \\
\mathrm{X} \\
\mathrm{X}\end{array}$ & $\begin{array}{l}\mathbf{X} \\
\mathbf{X} \\
\mathbf{X} \\
\mathbf{X} \\
\mathbf{X}\end{array}$ & $\begin{array}{l}\mathbf{X} \\
\mathbf{X} \\
\mathbf{X} \\
\mathbf{X} \\
\mathbf{X} \\
\mathbf{X} \\
\mathbf{X} \\
\mathbf{X} \\
\mathbf{X} \\
\mathbf{X}\end{array}$ & $\begin{array}{l}\mathrm{X} \\
\mathrm{X} \\
\mathrm{X} \\
\mathrm{X} \\
\mathrm{X}\end{array}$ & $\begin{array}{l}\mathrm{X} \\
\mathrm{X} \\
\mathrm{X} \\
\mathrm{X} \\
\mathrm{X}\end{array}$ & $\begin{array}{l}\mathbf{X} \\
\mathbf{X} \\
\mathbf{X} \\
\mathbf{X} \\
\mathrm{X}\end{array}$ & $\begin{array}{l}\mathrm{X} \\
\mathrm{X} \\
\mathrm{X} \\
\mathrm{X} \\
\mathrm{X} \\
\mathrm{X} \\
\mathrm{X} \\
\mathrm{X} \\
\mathrm{X} \\
\mathrm{X} \\
\mathrm{X} \\
\mathrm{X} \\
\mathrm{X}\end{array}$ \\
\hline Explained variance $\left(R^{2} \times 100\right)$ & $2.8 \%$ & $3.2 \%$ & $3.7 \%$ & $7.1 \%$ & $7.7 \%$ & $10.9 \%$ & $11.4 \%$ \\
\hline
\end{tabular}

'Since the survey $(N \approx 20,000)$ is held among a representative sample of the Dutch population the database comprises people with various health insurance plans. The adjuster 'insurance coverage' represents five variables that capture the major forms of coverage: sickness fund or private insurance (the former implies complete coverage for almost all types of medical care), coverage for GP care, coverage for outpatient specialist care, luxury insurance and level of deductible. The adjuster 'additional insurance coverage' represents three dummy variables that indicate whether the individual is covered for prescription drugs, for dentistry and for physiotherapy.

bocio-economic status is measured by profession ( 5 categories), income, education ( 6 levels) and ethnic minority.

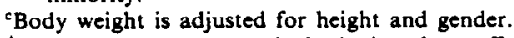

${ }^{d}$ The respondents were asked whether they suffered from one or more of 25 named chronic conditions; in addition there was an open category. The answers were weighted with the average medical consumption for each of the conditions. Some examples of these conditions are: rheumatism, heart conditions, hypertension, effects of stroke, diabetes, anaemia, asthma, hernia, cancer, serious consequences of accident. 
$X I$, which also contains self-rated general health status-perhaps a less objective measure of chronic illness-amounts to about three-quarters of what might be achievable.

Finally, the most comprehensive model (XII) contains all the risk factors that are available in this HIS dataset. The explained variance is $11.4 \%$, as compared to $10.9 \%$ for model XI, indicating that once health status is accounted for, the background characteristics are of little importance. The $11.4 \%$ achieved by model XII is distinctly better than the $7.8 \%$ that was obtained for the models in the previous section containing information on prior costs. This seems to support the hypothesis that, in the present context, direct indicators of health are preferable to more indirect indicators such as prior costs.

\section{Potential benefits of risk selection}

Until this point alternative models have been compared on the basis of their predictive performance, i.e. $R^{2}$ values and ability to predict correctly the costs of specific groups of individuals. If we want to assess an upper bound on the short term pecuniary gains which insurance organizations may achieve by unlimited risk selection, assuming no costs and no repercussions from selection-e.g. in terms of a bad reputation-we may compare capitation payments, based on a certain set of (global) adjusters, with cost predictions by insurers, based on a more comprehensive set of risk factors. Under the stated assumption it would be profitable for an insurer to reject all those applicants whose predicted costs are higher than their capitation payment (the bad risks) and to accept all the others (the good risks) [19]. The average expected profit per applicant depends on: (1) the adjusters included in the capitation formula; and (2) the cost predictions that insurers can make on the basis of additional risk factors. In this subsection the selection process is simulated by assuming, first, that the capitation payments are calculated via model III-3 and then assessing the potential gains when insurers subsequently use the other models to make (better) cost predictions [20]. Table 9 presents the results of this simulation. A second analysis simulates various alternative capitation formulae.

With respect to the interpretation of Table 9, it is important to note that a selection model is potentially more interesting to an insurer the better it identifies (the small group of) people with high costs. This depends on the difference per risk group between predicted costs and capitation payment, and the size of the group of bad risks. Moreover, the assumptions stated above are less restrictive than they seem: in theory it would be most profitable for an insurer to reject all the bad risks and accept all the good risks. However, the results can also be interpreted as indicating the expected gain that he would incur if he succeeded in rejecting (resp. accepting) one representative bad (resp. good) risk. Moreover, similar analyses for 1977 using the panel dataset of the previous sections, show that the profits of this selection procedure are not restricted to the year in which selection takes place. It appears that for the once selected groups, the profits in each of the following three years amount to about half the potential gains in the first year.

Table 9 shows that, given the global model III-3, selection by an insurer based on family size and employment status (model IV-2) may lead to the evasion of average losses of $21 \%$ for the $30 \%$ of applicants whose capitation payments are below predicted costs. For model V-2, which contains all available risk factors except health indicators, this percentage is undoubtedly higher. However, the potential gains of selection via IV-2 and V-2 are relatively modest in comparison to selection via the other models: by using information on chronic conditions (model IX) the insurer could evade losses of $96 \%$ on the capitation payments for individuals who represent bad risks (mainly people with chronic conditions). The remaining individuals, the good risks, have predicted costs that on average amount to only $66 \%$ of their capitation payment, resulting in an expected profit of $34 \%$ of the capitation payment on

Table 9. Potential profits of risk selection given a global capitation payment (model III-3)

\begin{tabular}{llcccc}
\hline \multirow{2}{*}{ Basis for selection } & $\begin{array}{c}\text { Percentage } \\
\text { of sample }\end{array}$ & $\begin{array}{c}\text { Capitation } \\
\text { payment }\end{array}$ & $\begin{array}{c}\text { Predicted } \\
\text { costs }\end{array}$ & $\begin{array}{c}\text { Percentage } \\
\text { difference }\end{array}$ \\
\hline model IV-2: & good risks & $70 \%$ & 1458 & 1329 & $-9 \%$ \\
model V-2: & bad risks & 30 & 1442 & 1739 & 21 \\
& good risks & 77 & 1500 & 1229 & -18 \\
bad risks & 23 & 1297 & 2198 & 69 \\
model IX: & good risks & 79 & 1373 & 912 & -34 \\
& bad risks & 21 & 1746 & 3430 & 96 \\
model X: & good risks & 78 & 1271 & 807 & -37 \\
& bad risks & 22 & 1673 & 3277 & 96 \\
model XII: & good risks & 77 & 1365 & 766 & -44 \\
& good risks & 23 & 1748 & 3762 & 115 \\
& bad risks & 74 & 1392 & 754 & -46 \\
\hline
\end{tabular}

"Model III-3 is used to calculate the (average) capitation payment while the (average) predicted costs are calculated via models IV-2 to XII. Average predicted costs almost equal average actual costs. The last column gives the percentage difference between average predicted cost and average capitation payment.

"Good (resp. bad) risks are defined as individuals with predicted costs below (resp. above) capitation payment. 
each enrolled individual. These percentages increase further if self-rated health and physical impairments are also used to discriminate between good and bad risks (model XI). For model XII, comprising all available risk factors, the average gains remain about the same, but the group of bad risks increases.

With regard to models IV-2 and V-2 it should be noted that, although the potential gains are small, the results have broader implications than those of the other models because risk factors such as socio-economic status, urbanization and supply can be employed for marketing purposes. This allows risk selection to occur even before an individual applies for insurance. In contrast, selection according to, for instance, health status can take place at the moment of application at the earliest. Besides, the costs of selective marketing are presumably small, both in real terms and in terms of (a bad) reputation.

We shall now simulate alternative capitation formulac so as to assess the maximum room for risk selection by using the best prediction available, i.e. based on model XII (Table 10). The starting point is a global model that accounts for age, gender, insurance coverage and region (model III-3), which is successively extended with other adjusters. The results again confirm the inadequacy of global capitation payments: the average predicted costs for the $26 \%$ of the sample who represent bad risks, are more than twice their average capitation payment. For the complementary group of good risks the predicted costs are about half the capitation payment. These figures improve little if the payments are also based on employment status and family size (model IV-2). The same conclusion applies when all available risk factors except health indicators, are employed as adjusters (model V-2). Only the inclusion of health indicators reduces the potential profits of risk selection by a significant degree: model $\mathrm{X}$, which accounts for chronic conditions and impairments, reduces the underpayment of bad risks to $52 \%$, and model XI, based also on self-rated health, further reduces this to $13 \%$.

It is interesting to note that the proportion of people labelled 'bad risks' is around $28 \%$ for all but the last selection and capitation model, indicating that an insurer who wants to apply selection strategies needs to consider only a minority of the applicants. This is, of course, a consequence of the fact that only a minority of the population suffers from chronic health problems.

Finally, it appears that the capitation payment for the average bad risk is higher than that for the average good risk in nearly all cases examined. This suggests that the proportion of bad risks among people with high capitation payments is relatively high. Thus, an elementary selection strategy would be to restrict selection primarily to those groups. In an additional analysis, not presented here, this strategy indeed appeared to be profitable, i.e. the absolute differences between capitation payment and predicted costs for the average bad risk and the average good risk within these groups were considerably higher than those for the representative bad and good risks.

\section{CONCLUSIONS AND DISCUSSION}

Generally speaking, this study, which employs Dutch panel and cross-section data, has produced results with respect to the capitation of health care insurers that are in line with findings of similar studies employing U.S. data-sources. This in itself is a remarkable finding in view of the large differences between the respective health care systems. It seems to imply that study results obtained in the U.S. are also relevant to the Dutch health care system. Moreover, results may be applicable as well to other countries contemplating similar capitation systems, e.g. Australia, Germany, Israel, New Zealand and Switzerland [2].

The estimation on a panel dataset $(N \approx 35,000)$ of a global capitation formula containing age, gender,

Table 10. Potential profits of maximum risk selection given various capitation formulae

\begin{tabular}{|c|c|c|c|c|c|}
\hline \multicolumn{2}{|c|}{ Capitation formulae } & $\begin{array}{l}\text { Percentage } \\
\text { of sample }\end{array}$ & $\begin{array}{c}\text { Capitation } \\
\text { payment }\end{array}$ & $\begin{array}{l}\text { Predicted } \\
\text { costs }\end{array}$ & $\begin{array}{l}\text { Percentage } \\
\text { difference }\end{array}$ \\
\hline \multirow[t]{2}{*}{ model III-3: } & good risks ${ }^{b}$ & $74 \%$ & 1392 & 754 & $-46 \%$ \\
\hline & bad risks & 26 & 1626 & 3439 & 111 \\
\hline \multirow[t]{2}{*}{ model IV-2: } & good risks & 74 & 1383 & 771 & -44 \\
\hline & bad risks & 26 & 1657 & 3433 & 107 \\
\hline \multirow[t]{2}{*}{ model V-2: } & good risks & 74 & 1352 & 827 & -39 \\
\hline & bad risks & 26 & 1731 & 3235 & 87 \\
\hline \multirow[t]{2}{*}{ model IX: } & good risks & 72 & 1335 & 936 & -30 \\
\hline & bad risks & 28 & 1758 & 2790 & 59 \\
\hline \multirow[t]{2}{*}{ model $\mathrm{X}$ : } & good risks & 70 & 1260 & 895 & -29 \\
\hline & bad risks & 30 & 1592 & 2426 & 52 \\
\hline \multirow[t]{2}{*}{ model XI: } & good risks & 56 & 1430 & 1277 & -11 \\
\hline & bad risks & 44 & 1482 & 1672 & 13 \\
\hline
\end{tabular}

Model XII, comprising all available risk factors, is used to calculate the (average) predicted costs while the (average) capitation payments are calculated on the basis of models III-3 to XI. Average predicled costs are approximately equal to average actual costs. The last column gives the percentage difference between average predicted costs and average capitation payment.

${ }^{b}$ Good (resp. bad) risks are defined as individuals with predicted costs below (resp. above) capitation payment. 
insurance coverage and region, yielded an $R^{2}$ value of only 0.024 . This is less than $1 / 5$ of the theoretically maximum achievable, which was estimated to be 0.138 . This implies that a global capitation formula will systematically overpay for some groups and underpay for others and thus stimulate risk selection by insurers. It also will lead to unfair competition because at present the latter groups are not randomly distributed among the various insurers. Several Dutch studies have shown, for example, that the (public) sickness funds have a relatively high proportion of bad risks (taking differences in age-sex distribution into account; cf. [21]). Consequently, a global capitation formula is neither fair in the short term, nor will it achieve a stable insurance market in the long term.

In view of the low $R^{2}$ value for a model of global capitation, it is not surprising that it appeared to be highly lucrative for insurance companies to select among their present insured on the basis of past utilization and expenditure. As this type of information is readily available to every insurer, it is both imperative and administratively feasible to include prior total costs in the capitation formula in the short term.

The inclusion of prior total costs as adjuster in the capitation formula, almost tripled the explained variance, which is now reaching a value of 0.071 . Although this is more than half the maximum achievable value, the predictive performance of this capitation formula was poor for groups formed on four indicators of health status in the base year. For example, the subgroup (comprising some $10 \%$ of the study population) with more than Dfl. 100 of expenses on prescription drugs in the base year, still had costs that were $47 \%$ above capitation payment 4 years later, the payment being based on 6 adjusters, namely age, gender, insurance coverage, region and prior total costs. Smaller but significant discrepancies were also found for groups formed on other types of health care costs and health indicators. The relevance of these findings in the context of risk selection is, that insurers can distinguish various types of expenditure. Moreover, many Dutch insurance organizations routinely collect better indicators of chronic health status than those used here, namely diagnostic information on (previous) hospitalizations of their insured. Thus, even such an advanced capitation formula leaves considerable room for risk selection.

Capitation formulae based on prior costs seem to score well according to the four major criteria for evaluating alternative payment models mentioned by Epstein and Cumella [17]: predictive performance, administrative feasibility, invulnerability to manipulation, and absence of adverse incentives. Prior costs appear to predict a substantial proportion of variance, it is readily available in the Dutch case, it is little susceptible to manipulation (though some monitoring will undoubtedly be necessary), and implies few adverse incentives (as the impact of prior costs on future payments appeared to be only $25 \%$ ). However, this adjuster scores poorly on an additional criterion that is important in the Dutch context of capitation, i.e., only those differences in costs between insurers should be accounted for that can be traced to differences in (chronic) health status. The importance of this criterion lies in the fact that the influence on expenditures of, for example, prices, supply, propensity to consume, income, extent of insurance coverage, and cost-containment policies, is, in the long term, supposed to be the responsibility of the health insurers themselves. Such factors would indirectly be taken into account when capitation payments are partly based on prior costs.

A second problem with prior-year's costs is, that it is subject to much random variation, i.e. it is a poor proxy of what we would actually like to measure, namely chronic health conditions. Using prior-year's cost directly as an adjuster would mean compensating for self-limited illnesses, which is clearly not the intension of capitation. The solution may be to use past expenditures from longer periods rather than just one year, to identify more accurately those who are suffering from chronic conditions. For instance, it is likely that these people incur some expenditures (especially for outpatient care) each year because they are generally under regular medical surveillance. Furthermore, diagnostic information on non-discretionary past hospitalizations could be used as well. Such information may be incorporated in a capitation formula in the form of Diagnostic Cost Groups [4].

In the short term, prior costs of prescription drugs also could be considered as an adjuster because it has good predictive ability and seems administratively feasible. However, it may be vulnerable to manipulation and may promote adverse incentives.

We conclude, as does Lubitz [22], that "for policy reasons the most practical adjusters at present are measures based on prior use of services". In the long term, however, better adjusters have to be found to prevent risk selection and increase distributional fairness. Obviously, solutions to risk selection may also be found in additional procompetitive regulation like risk-related flat premiums, risk sharing between the Central Fund and insurers, qualification of insurance contracts, special arrangements for the enrolment procedure, monitoring of the quality of services and ethical codes for insurers. Such supplementary solutions are discussed in full by van de Ven and van Vliet [2]

In view of the above mentioned drawbacks of prior costs, it seems imperative that in the long term chronic conditions should be taken into account more explicitly. In an attempt to investigate the merits of this type of adjuster, we analyzed data from a health interview survey covering a representative sample of the Dutch population. The most comprehensive capitation formula estimated on this dataset, comprising several indicators of health status such as physical impairments, self-rated health status, and 25 
common chronic conditions (weighted by their-expected costs), yielded an $R^{2}$ value of 0.114 , which may account for about $3 / 4$ of the maximum achievable $R^{2}$. In particular, chronic conditions appeared to have strong predictive ability.

Various types of information that insurers might use to discriminate good and bad risks, given global capitation payments, were explored, using the survey data. The results showed that selection opportunities also lie in selective marketing (based on socio-economic status), and in selection at enrolment (based on for instance health status). The estimated maximum selection profits reach approx $100 \%$ of (global) capitation payments in some cases. That is, by using information on, for example chronic conditions to select risks, insurers are, in theory, able to evade losses of about $100 \%$ on the capitation payments for individuals who represent a bad risk. In practice, these gains would not be realised completely because of selection costs, both financially and in terms of reputation, which were not taken into account. However, given a global capitation payment, the potential profits are so high and can be obtained so easily that it is highly unlikely that insurers will not yield to the temptation to engage in selection.

Assuming that the health indicators available in the survey dataset, and the information on total prior costs available in the panel dataset, explain to some extent different portions of the variance in health care expenditures [23], the above summarized results suggest that a capitation payment based on both health indicators and prior costs will prevent risk selection to a great extent.

Acknowledgements - The authors gratefully acknowledge the assistance of Erik van Barneveld with the computations for this study. They thank three anonymous referees and Andrew Street for their helpful comments on a previous version of this article and the health insurance organization "Zilveren Kruis" for providing the dataset analyzed.

\section{REFERENCES}

1. Werken aan zorgvernieuwing, Tweede Kamer, 1989-1990, 21545, nr. 2, May 1990.

2. Van de Ven W. P. M. M. and Van Vliet R. C. J. A. How can we prevent cream skimming in a competitive health insurance market? The great challenge for the 90's. Health Economics Worldwide (Edited by Zweifel P. and Frech H. E.). Kluwer, Amsterdam, 1992. This paper gives a fuller description of the policy proposals of the Dutch government as well as theoretical considerations with respect to risk selection, a review of the relevant literature and suggestions for additional procompetitive regulation.

3. Newhouse J. P. Rate adjusters for Medicare under capitation. Hlth Care Finan. Rev. annual suppl., pp. 45-55, 1986.

4. Phrases related to 'explaining' and 'predicting' are used interchangeably in this paper without imploying different meanings, unless explicitly stated otherwise. Findings by Ash A. et al. Adjusting medicare capitation payments using prior hospitalization data. Hlth Care Finan. Rev. 10, (4), 17.29,1989, as well as the results from our own analyses, show that taking this difference into account has virtually no effect on the major conclusions.

5. About half of these dropouts concerned people who were compelled to switch to the (compulsory) sickness fund insurance and about $5 \%$ were people who died.

6. Welch W. P. Regression toward the mean in medical care costs, implications for biased selection in Health Maintenance Organizations. Med. Care 23, (11), 1234-1241, 1985.

7. Lubitz J., Beebe $J$, and Riley R. Improving the Medicare HMO payment formula to deal with biased selection. In Advances in Health Economics and Health Services Research (Edited by Scheffler R. M. and Rossiter L. F.), Vol. 6. JAI Press, London, 1985.

8. Beebe J. C. Medicare reimbursement and regression to the mean. Hlth Care Finan. Rev. 9, (3), 9-22, 1988.

9. In this respect the (intended) capitation of health insurers in the Netherlands differs from the AAPCC: the former should, ideally, only account for health status because effects of other risk factors are supposed to be the responsibility of the insurers whereas in the AAPCC such factors may play a role as well because it should equate the costs that beneficiaries would have had in the fee-for-services sector.

10. An Appendix to this article containing the details of these analyses, is available from the authors upon request.

11. Newhouse J. P., Manning W. G., Keeler E. B. and Sloss E. M. Adjusting capitation rates using objective health measures and prior utilization. Hlth Care Financ. Rev. 10, (3), 41-54, 1989.

12. Ellis R. P. The effect of prior-year health expenditures on health coverage plan choice. In Advances in Health Economics and Health Services Research (Edited by Scheffler R. M. and Rossiter L. F.), Vol. 6. JAI Press, London, 1985.

13. Van Vliet R. C. J. A. Quantifying Risk Selection in Case of Global Capitation Formulae, a Micro Simulation Study (Kwantificering van risico-selectie in een globaal normuitkeringensysteem, een micro-simulatie studie), Erasmus University, 1990.

14. Duan N., Manning W. G., Morris C. N. and Newhouse J. P. A comparison of alternative models for the demand for medical care. J. Business Econ. Stat. 1, (2), $115-126,1983$.

15. Gerritse R., Janssen R. T. J. D. and Poelert J. D. Towards a Budgetsystem for the Central Fund (Naar een verdeelstelsel voor de Centrale Kas), report commissioned by the Dutch government, 1989.

16. Beebe J. C., Lubitz J. and Eggers P. Using prior utilization to determine payments for Medicare enrollees in health maintenance organizations. Hlth Care Finan. Rev. 6, (3), 27-38, 1985.

17. Epstein A. M. and Cumella E. J. Capitation payment: using predictors of medical utilization to adjust rates. Hlth Care Finan. Rev. 10, (1), 51-69, 1988.

18. This database may present the post-diction problem described by Manning, W. G., Newhouse J. P. and Ware J. E. The status of health in demand estimation; beyond excellent, good, fair, poor. In Economic Aspects of Health (Edited by Fuchs V. R.). NBER, The University of Chicago Press, 1984. This problem can be described as follows: the dependent variable-medical care utilization-is measured over a certain time period while the independent-health status-variables refer implicitly or explicitly to the same period. (This was the reason for not using in the analysis data on days of illness in the period of two weeks before the surveywhich was available in the dataset.) Since the most important health indicators refer to physical impairments and the presence or absence of 25 named severe chronic diseases, we are reasonably confident that this is not a major problem in the present analysis. 
19. Or to remove insured individuals who are predicted to be bad risks and to keep the good risks.

20. The expected profit of risk selection by means of making better cost predictions, given a certain capitation formula, depends largely on the difference in $R^{2}$ values between the two formulae concerned. Newhouse et al. op. cit. derive a relation between these two quantities. This derivation is not applied here because it is based on assumptions, with regard to the distribution of expenditures, which are clearly rejected in pur database
21, van de Ven W. P. M. M. and van Vliet R. C. J. A. Effects of cost-sharing in the health care sector. Gezondheid \& Samenleving 4, (6), 238-244, 1985.

22. Lubitz $\mathbf{J}$. Health status adjustments for Medicare capitation. Inquiry 24, 362-375, 1987.

23. This assumption is supported by the findings of Newhouse et al. op. cit. and Howland J., Stokes J., Crane S. C. and Belanger A. J. Adjusting capitation using chronic disease risk factors: a preliminary study. Hlth Care Finan. Rer. 9(2), 15-23, 1987. 